\title{
Impact of the SYNTAX Score on Risk Stratification after Percutaneous Coronary Intervention in Non-Selected Patients
}

\author{
Roberto Ramos Barbosa ${ }^{1}$, J. Ribamar Costa Jr. ${ }^{1}$, Fausto Feres ${ }^{1}$, Alexandre Abizaid ${ }^{1,2}$, Ricardo A. Costa ${ }^{1,2}$, \\ Dimytri Siqueira', Rodolfo Staico', Vinicius Esteves ${ }^{1}$, Said Assaf Neto', Sergio Braga', \\ Luiz Alberto Mattos ${ }^{1}$, Galo Maldonado ${ }^{3}$, Luiz Fernando Tanajura ${ }^{1}$, Marinella Centemero', \\ Áurea Jacob Chaves', Amanda G. M. R. Sousa' ${ }^{1}$, J. Eduardo Sousa'
}

\begin{abstract}
Background: The SYNTAX score was developed as an angiographic tool to grade the complexity of coronary artery disease in patients with three-vessel and/or left main disease. The role of this score in predicting clinical outcomes after percutaneous coronary intervention $(\mathrm{PCl})$ in non-selected patients treated in the daily clinical practice of a referral centre was evaluated. Methods: Analysis of patients undergoing PCl from March to September of 2009, and at the 12-month follow-up. Patients were divided into tertiles according to the SYNTAX score. The primary endpoint included major adverse cardiac events (MACE) - death, non-fatal acute myocardial infarction, and target-vessel revascularisation. The ability of the SYNTAX score to predict MACE was assessed by the receiver operator characteristic (ROC) curve. Results: Two hundred and thirty-four patients with a mean SYNTAX score of $11.6 \pm 6.2$ points were included. Tertile I had a SYNTAX score $\leq 9$ (average 5.9); tertile $\mathrm{II},>9$ and $\leq 13$ (average 10.8); and tertile III, > 13 (average 18.3). During the clinical follow-up of $7.2 \pm 4.9$ months, the incidence of MACE was greater in tertile III than in tertiles I and II $(2.5 \%$ vs. $6.4 \%$ vs. $14.1 \%$; $P=0.0075)$. The ROC curve showed an area under the curve of $0.667(\mathrm{P}=0.012)$, indicating a moderate ability to anticipate the occurrence of MACE in this population. Conclusions: The SYNTAX score proved to be useful in predicting the occurrence of MACE after $\mathrm{PCl}$ in patients treated in clinical practice.
\end{abstract}

DESCRIPTORS: Coronary artery disease. Angioplasty. Stents. Drug-eluting stents. Prognosis.

\section{RESUMO}

Impacto da Utilização do Acesso Radial na
Ocorrência de Sangramento Grave entre Idosos
Submetidos a Intervenção Coronária Percutânea

Introdução: O escore SYNTAX foi desenvolvido como ferramenta para graduar a complexidade angiográfica da doença arterial coronária em pacientes com acometimento de três vasos e/ou com lesão de tronco. Avaliamos seu papel em predizer desfechos clínicos após intervenção coronária percutânea (ICP) em pacientes não-selecionados, tratados na prática diária de um hospital de referência. Métodos: Análise de pacientes submetidos a ICP entre março e setembro de 2009 e acompanhados por até 12 meses. Os pacientes foram divididos em tercis de acordo com o escore SYNTAX. O desfecho primário foi composto de eventos cardíacos adversos maiores (ECAM) óbito, infarto agudo do miocárdio não-fatal e revascularização do vaso-alvo. O desempenho do escore SYNTAX em predizer ECAM foi avaliado pela curva ROC (Receiver Operator Characteristic). Resultados: Foram incluídos 234 pacientes com escore SYNTAX médio de $11,6 \pm 6,2$ pontos. O tercil I apresentou escore SYNTAX $\leq 9$ (média de 5,9); o tercil II, $>9$ e $\leq 13$ (média de 10,8); e o tercil III, > 13 (média de 18,3). No seguimento clínico de 7,2 $\pm 4,9$ meses, a incidência de ECAM foi maior no tercil III em comparação com os tercis I e II $(2,5 \%$ vs. $6,4 \%$ vs. $14,1 \% ; P=0,0075)$. A curva ROC mostrou área sob a curva de $0,667(\mathrm{P}=0,012)$, indicando moderada capacidade de prever a ocorrência de ECAM nessa população. Conclusões: O escore SYNTAX mostrou ser útil em prever a ocorrência de ECAM em pacientes pós-ICP tratados na prática clínica diária.

DESCRITORES: Doença das coronárias. Angioplastia. Stents. Stents farmacológicos. Prognóstico.

\footnotetext{
Instituto Dante Pazzanese de Cardiologia - São Paulo, SP, Brazil.

${ }^{2}$ Cardiovascular Research Center - São Paulo, SP, Brazil.

${ }^{3}$ Instituto de Ensino e Pesquisa - Hospital do Coração - Associação do Sanatório Sírio - São Paulo, SP, Brazil.

Correspondence to: Roberto Ramos Barbosa. Avenida Dante Pazzanese, 500 - Vila Mariana - São Paulo, SP, Brazil - CEP 04012-909

E-mail: roberto.rb@cardiol.br

Received on: 12/5/2011 • Accepted on: 2/17/2012
} 
$\mathrm{T}$ he SYNTAX score was developed as an angiographic tool to grade the complexity of coronary artery disease (CAD), and it has been used to determine the prognosis of patients with triarterial CAD and/or those with lesions in the left main coronary artery; this score aids decision-making regarding the best revascularisation strategy, whether percutaneous or surgical. ${ }^{1-4}$ Recent data also indicate the usefulness of the SYNTAX score to predict the development of periprocedural myocardial infarction in patients undergoing elective percutaneous coronary intervention $(\mathrm{PCl}) .^{5}$

The SYNTAX study, which first described the score, compared late clinical outcomes in patients with multivessel disease treated with $\mathrm{PCl}$ and paclitaxel-eluting stents versus coronary artery bypass graft (CABG) surgery. ${ }^{2}$ The unfavourable $\mathrm{PCI}$ results in patients with higher anatomic complexity confirmed the limitation of interventionist techniques in such cases.

Even with advances in $\mathrm{PCl}$ techniques and the availability of new devices, such as second-generation of drug-eluting stents, currently, the percutaneous treatment of CAD remains limited to cases of low to moderate anatomic complexity. Presently, in Brazil, drug-eluting stents are not available in the public health system, and the public health system does not reimburse the institution when more than two stents are implanted in the same procedure.

In the present study, the SYNTAX score was applied to a non-selected patient population treated with $\mathrm{PCI}$ in a tertiary centre within the public health system in the state of São Paulo; its performance as a prognostic tool was evaluated immediately in-hospital and for medium-term evolution.

\section{METHODS}

This was a retrospective study performed in a single centre using a database with prospectively-collected data, which evaluated the SYNTAX angiographic score regarding in-hospital and medium-term clinical outcomes of patients undergoing $\mathrm{PCl}$ attended to in daily clinical practice.

Patients treated with drug-eluting and bare-metal stents between March and September 2009, either electively or due to acute coronary syndrome, were included. All interventions were performed according to the indications established in the current guidelines ${ }^{6}$ following standard techniques, and all patients signed an informed consent before the procedure.

Patients who had all arterial territories treated in a single procedure and those who underwent staged procedures, provided they were performed within 30 days of the index procedure, were included. Patients who underwent previous $\mathrm{PCl}$ with stent implantation or CABG surgery were excluded. Patients who were not followed-up in the institution after $\mathrm{PCl}$ were also excluded.
Information on the clinical characteristics, procedures and adverse events was obtained from records in the data bank and medical records.

Pre-procedure coronary angiographies of all patients included in this study were analysed, and the SYNTAX score was calculated by two interventional cardiologists using instructions and programs available at the official SYNTAX score website (www.syntaxscore.com). Patients were divided into tertiles according to the SYNTAX score and were evaluated regarding the development of in-hospital and late adverse events.

Major adverse cardiac events (MACE - outcomes such as cardiac death, non-fatal acute myocardial infarction, and new revascularisation of the targetvessel by clinical indication) in late follow-up were considered the primary outcome. All deaths were considered to be from cardiac cause unless another cause had been established. Confirmation of acute myocardial infarction was achieved by evidence of elevated serum markers of myocardial necrosis ( $>$ three times the upper limit for creatine kinase-MB fraction) associated with symptoms or electrocardiographic evidence of myocardial ischemia. Q-wave infarctions were defined by new pathologic $\mathrm{Q}$ waves on electrocardiogram (two or more contiguous derivations) or new left bundle branch block in addition to the biomarker changes. Revascularisation of the targetvessel was defined as new revascularisation of the treated coronary artery. Chronic renal disease was defined as the presence of a creatinine clearance $<60 \mathrm{~mL} / \mathrm{min}$ before the procedure.

Secondary outcomes included the success of the procedure, isolated death rates, non-fatal myocardial infarction, and revascularisation of the target-vessel, in addition to definitive or probable stent thrombosis (according to the definition of the Academic Research Consortium - ARC). ${ }^{\text {? }}$

Categorical variables were expressed as absolute frequencies and percentages, and continuous variables were expressed as the mean and standard deviation. Data were compared according to the tertiles of the SYNTAX score and by using the chi-squared test or Fisher's exact test for categorical variables, or ANOVA for continuous variables. P-values $<0.05$ were considered statistically significant. The capacity of the SYNTAX score to discriminate patients with MACE was evaluated by the receiver operating characteristic (ROC) curve. The SAS and XLSTAT 2011 statistical programs were used.

\section{RESULTS}

In the period evaluated, 234 patients undergoing $\mathrm{PCl}$ fulfilled inclusion criteria. The mean age of the population was $59.8 \pm 9.7$ years, and $71.4 \%$ of the patients were males. Two hundred ninety-seven vessels were treated with the implantation of 339 stents (mean of $1.44 \pm 0.32$ stents per patient and $1.14 \pm 0.11$ stents 
per vessel). The mean follow-up time was $7.2 \pm 4.9$ months.

The SYNTAX score ranged from 1 to 57.5 points, with a predominance of patients with low SYNTAX scores (0 to 22), according to the original classification (222 patients or $94.8 \%), 11(4.7 \%)$ patients had an intermediate SYNTAX score (23 to 32), and only one patient $(0.4 \%)$ present an elevated SYNTAX score $(\geq 33)$. Specifically in the latter case, it was decided to perform $\mathrm{PCl}$ due to the presence of severe comorbidities and an elevated surgical risk for CABG surgery.

The mean SYNTAX score in this population was $11.6 \pm 6.2$ points. The median score in the population was 11 points. Patients were divided by tertiles, each with 78 patients. Patients in tertile I had a SYNTAX score $\leq 9$; in tertile II, patients had a SYNTAX score $>9$ and $\leq 13$; and in tertile III, patients had a SYNTAX score $>13$. In the study population, the mean SYNTAX scores for tertiles I, II, and III were, respectively, 5.9, 10.8 , and 18.3 .

The prevalence of risk factors for CAD was progressively greater with increased SYNTAX score, with a higher proportion of diabetic and dyslipidaemic patients in tertile III (Table 1).

Regarding the types of stents implanted, the majority of patients $(81.6 \%)$ received bare-metal stents. There was no difference in the use of drug-eluting stents in tertiles I, II, or III $(18.9 \%, 17.1 \%$, and $21.9 \%$;
$P=0.57)$. The coronary territory most frequently treated was that of the left anterior descending artery, accounting for $38 \%$ of the procedures (113 interventions). Procedural success was obtained in $98.7 \%$ of the cases in tertile I, in $96.2 \%$ of the cases in tertile II, and in $94.8 \%$ of the cases in tertile III ( $P=0.17)$. Table 2 presents the angiographic characteristics and procedure data.

Differences among the tertiles for in-hospital MACE were not observed, but differences were observed in late MACE, with a higher number of combined events in tertile III compared with tertiles I and II $(2.5 \%$ in tertile I, $6.4 \%$ in tertile II, and $14.1 \%$ in tertile III; $\mathrm{P}=0.0075$ ) (Table 3 ). Regarding secondary outcomes, the incidence of isolated adverse events was greater in the group with higher SYNTAX scores (tertile III), but this difference was not statistically significant. During the follow-up period, stroke was not diagnosed, and cases of definitive stent thrombosis were not documented. One of the two deaths observed in tertile III fulfilled the criteria for probable stent thrombosis (unexplained death within 30 days of the procedure). The other death was attributed to complications secondary to decompensated congestive heart failure.

The ROC curve, constructed to measure the performance of the SYNTAX score, showed an area under the curve of 0.667 ( $P=0.012)$, demonstrating a moderate capacity to predict the development of MACE in this population (Figure 1).

TABLE 1

Baseline Clinical Characteristics

\begin{tabular}{|c|c|c|c|c|}
\hline Variables & $\begin{array}{c}\text { Tertile I } \\
(n=78)\end{array}$ & $\begin{array}{l}\text { Tertile II } \\
(n=78)\end{array}$ & $\begin{array}{c}\text { Tertile III } \\
(n=78)\end{array}$ & $\mathbf{P}$ \\
\hline Mean age, years & $58.6 \pm 8.9$ & $60.2 \pm 9.9$ & $61.4 \pm 9.6$ & 0.71 \\
\hline Male gender, n (\%) & $57(73.1)$ & $48(61.5)$ & $62(79.5)$ & 0.34 \\
\hline Hypertension, n (\%) & $65(83.3)$ & $70(89.7)$ & $71(91)$ & 0.15 \\
\hline Diabetes mellitus, n (\%) & $18(23.1)$ & $28(35.9)$ & $36(46.1)$ & 0.002 \\
\hline Dyslipidaemia, n (\%) & $47(60.2)$ & $56(71.8)$ & $62(79.5)$ & 0.008 \\
\hline Smoking, n (\%) & $16(20.5)$ & $11(14.1)$ & $17(21.8)$ & 0.21 \\
\hline Chronic kidney disease, n (\%) & $4(5.1)$ & $7(8.9)$ & $8(10.2)$ & 0.22 \\
\hline Clinical presentation, n (\%) & & & & 0.19 \\
\hline Asymptomatic & $17(21.8)$ & $12(15.4)$ & $11(14.1)$ & \\
\hline Stable angina & $45(57.7)$ & $45(57.7)$ & $48(61.5)$ & \\
\hline ACS without ST-segment elevation & $10(12.8)$ & $12(15.4)$ & $13(16.6)$ & \\
\hline AMI with ST-segment elevation & $6(7.7)$ & $9(11.5)$ & $6(7.7)$ & \\
\hline
\end{tabular}

$\mathrm{n}=$ number of patients; $\mathrm{ACS}=$ acute coronary syndrome; AMI = acute myocardial infarction. 
TABLE 2

Angiographic and Procedure Characteristics

\begin{tabular}{|c|c|c|c|c|}
\hline Variables & $\begin{array}{l}\text { Tertile I } \\
(\mathbf{n}=78)\end{array}$ & $\begin{array}{l}\text { Tertile II } \\
(\mathbf{n}=78)\end{array}$ & $\begin{array}{l}\text { Tertile III } \\
(\mathbf{n}=78)\end{array}$ & $\mathbf{P}$ \\
\hline Number of coronary arteries treated & 86 & 96 & 115 & 0.32 \\
\hline Number of stents implanted & 95 & 111 & 132 & 0.13 \\
\hline Coronary arteries with $\geq 70 \%$ lesion, $\mathrm{n}(\%)$ & & & & $<0.001$ \\
\hline Uniarterial & $64(82.1)$ & $47(60.2)$ & $14(17.9)$ & \\
\hline Biarterial & $12(15.4)$ & $20(25.6)$ & $32(41.1)$ & \\
\hline Triarterial & $2(2.5)$ & $11(14.1)$ & $32(41.1)$ & \\
\hline \multicolumn{5}{|l|}{$\begin{array}{l}\text { Number of coronary arteries treated according } \\
\text { to the anatomy }(\%)\end{array}$} \\
\hline LMCA & 0 & 0 & $4(3.5)$ & 0.07 \\
\hline LAD & $32(37.2)$ & $36(37.5)$ & $45(39.1)$ & 0.78 \\
\hline LCx & $26(30.2)$ & $23(23.9)$ & $26(22.6)$ & 0.22 \\
\hline RCA & $28(32.5)$ & $37(38.5)$ & $40(34.7)$ & 0.82 \\
\hline \multicolumn{5}{|l|}{ Number of stents used according to type (\%) } \\
\hline Drug-eluting & 18 (18.9) & $19(17.1)$ & $29(21.9)$ & 0.57 \\
\hline Bare-metal & $77(81.1)$ & $92(82.9)$ & $103(78.1)$ & 0.34 \\
\hline \multicolumn{5}{|l|}{$\begin{array}{l}\text { Number of lesions according to anatomic } \\
\text { complexity }(\%)\end{array}$} \\
\hline Chronic total occlusion & 0 & $4(4.1)$ & $13(11.3)$ & $<0.001$ \\
\hline Bifurcation & $9(10.4)$ & $22(22.9)$ & $37(32.2)$ & $<0.001$ \\
\hline Moderate/severe calcification & 0 & $11(11.5)$ & $26(22.6)$ & $<0.001$ \\
\hline Severe tortuosity & $5(5.8)$ & $12(12.5)$ & $14(12.2)$ & 0.12 \\
\hline B2/C type lesions & $16(18.6)$ & $43(44.8)$ & $81(70.4)$ & $<0.001$ \\
\hline
\end{tabular}

\section{DISCUSSION}

In this analysis, the SYNTAX score appeared to be capable of predicting MACE after $\mathrm{PCl}$ in a general population in which most patients treated had low angiographic complexity according to the original classification of the SYNTAX study.

The SYNTAX score is based on adding the complexity points of each lesion $>50 \%$ of the cross-sectional area of the vessel, which are proportional to the lesion complexity as identified on coronariography. ${ }^{3}$ Even though its importance in selecting the appropriate myocardial revascularisation technique for different presentations of multiarterial CAD cannot be disputed, the SYNTAX score's usefulness remains uncertain for patients with one- or two-vessel disease.

In the SYNTAX trial, the high score group $(\geq 33)$ undergoing $\mathrm{PCI}$ showed higher MACE and adverse cardiac and cerebrovascular event rates (MACCE) compared with the group undergoing CABG surgery $(23.4 \%$ vs. $10.9 \%$; $\mathrm{P}=0.001)$. Additionally, the rate of combined outcomes of death, acute myocardial infarction, and stroke showed a tendency to be more elevated in the group treated percutaneously $(11.9 \%$ vs. $7.6 \%$; $\mathrm{P}=0.08) .{ }^{1}$ Previously, similar results had been reported in the three years of evolution of patients in the Arterial Revascularisation Therapies Study Part II - Sirolimus-eluting stents for the treatment of patients with multivessel de novo coronary artery lesions (ARTS II). In that study, multivariate analysis was performed to determine the independent predictors of MACE. It was demonstrated that the SYNTAX score was one of the strongest predictors of MACE (odds ratio $[\mathrm{OR}] 1.43,95 \%$ confidence interval $[95 \% \mathrm{Cl}]$ 1.08-1.90; $\mathrm{P}=0.014)$, as was diabetes mellitus (OR $1.76,95 \% \mathrm{Cl} 1.13-2.74 ; \mathrm{P}=0.012) .{ }^{8}$ This evidence was used to determine which patients would be ineligible for percutaneous revascularisation techniques, based 
TABLE 3

Incidence of Major Adverse Cardiac Events

\begin{tabular}{|c|c|c|c|c|}
\hline Event & $\begin{array}{l}\text { Tertile I } \\
(n=78)\end{array}$ & $\begin{array}{l}\text { Tertile II } \\
(n=78)\end{array}$ & $\begin{array}{l}\text { Tertile III } \\
(n=78)\end{array}$ & $\mathbf{P}$ \\
\hline \multicolumn{5}{|l|}{ In-hospital, n (\%) } \\
\hline Death & 0 & 0 & 0 & NA \\
\hline Myocardial infarction & $1(1.3)$ & $3(3.8)$ & $4(5.1)$ & 0.17 \\
\hline Target-vessel revascularisation & 0 & 0 & 0 & NA \\
\hline MACE & $1(1.3)$ & $3(3.8)$ & $4(5.1)$ & 0.17 \\
\hline \multicolumn{5}{|l|}{ Late phase, n (\%) } \\
\hline Death & 0 & 0 & $2(2.5)$ & 0.24 \\
\hline Myocardial infarction & 0 & 0 & $2(2.5)$ & 0.24 \\
\hline Target-vessel revascularisation & $1(1.3)$ & $2(2.5)$ & $3(3.8)$ & 0.31 \\
\hline MACE & $1(1.3)$ & $2(2.5)$ & $7(8.9)$ & 0.02 \\
\hline Cumulative MACE, n (\%) & $2(2.5)$ & $5(6.4)$ & $11(14.1)$ & 0.0075 \\
\hline
\end{tabular}

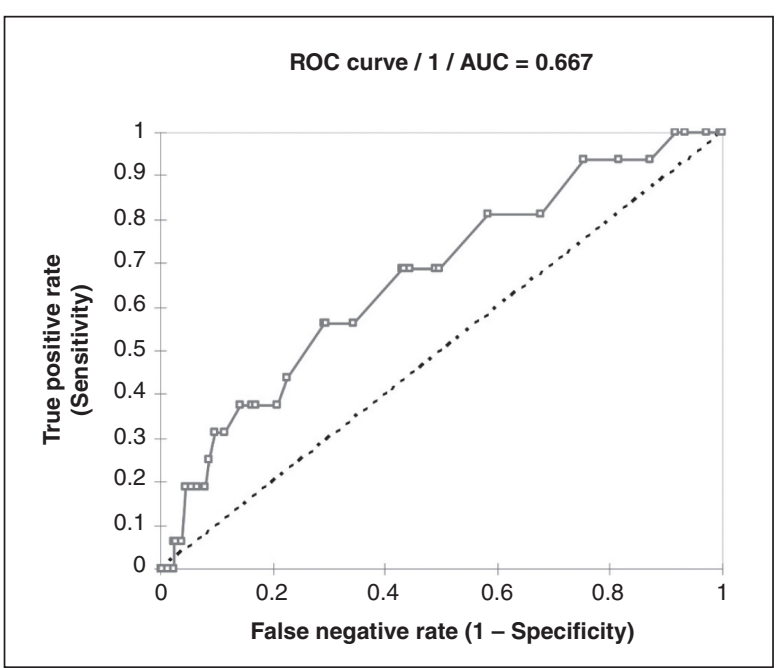

Figure 1 - SYNTAX score ROC curve used to predict major cardiac adverse events. $\mathrm{A} \cup \mathrm{C}=$ area under the curve; $\mathrm{ROC}=$ receiver operating characteristic.

on higher anatomic complexity.

Other studies also analysed the SYNTAX score in different populations. A subanalysis of the Limus Eluted from a Durable versus Erodable Stent Coating (LEADERS $)^{9}$ study found a mean SYNTAX score of $13.3( \pm 8.7)$ in a sample of 1,397 patients undergoing $\mathrm{PCI}$. A lower MACE-free survival rate was observed in the tertile with higher SYNTAX scores (low $=92.2 \%$; intermediate =
91.1\%; and high $=84.6 \% ; \mathrm{P}=0.001)$. Higher mortality rates $($ low $=1.5 \%$; intermediate $=2.1 \%$; and high $=5.6 \% ; \mathrm{P}=0.002$ ) and higher rates of target-vessel revascularisation were also observed (low $=6.3 \%$; intermediate $=7.8 \%$; and high $=11.3 \% ; \mathrm{P}=0.001) .{ }^{10}$ The similarity of the mid-range SYNTAX score of that study with the present analysis is emphasised.

The Comparison of Zotarolimus-Eluting and Everolimus-Eluting Coronary Stents study, which analysed 2,292 patients, found a mean SYNTAX score of 14.7 points with a 12-month incidence of MACE of approximately $8.2 \%$ in the group of patients who received zotarolimus-eluting stents and of approximately $8.3 \%$ in the group who received everolimus-eluting stents $(P=0.42)$. Additionally, the global rate of combined outcomes, which included all cardiovascular events, was $14.6 \% .^{11}$ These rates are smaller than the event rate of $18.3 \%$ reported by the angiographic group in the Fractional Flow Reserve Versus Angiography for Multivessel Evaluation (FAME) study, which had a similar SYNTAX score distribution. In this last study, 1,005 patients with multivessel CAD were randomised for angiography or fractional flow reserve-guided $\mathrm{PCl}$, and the SYNTAX score of both groups was 14.5 points. $^{12}$

The authors believe that each institution should know the angiographic profile of the patients it treats and determine the clinical outcomes profile in that population. In addition to representing good medical practice, this model can be used for institutional quality control. 


\section{Limitations of the study}

Although this study provides important information on the use of the SYNTAX score in daily $\mathrm{PCI}$ practice, it has some limitations. The first and main limitation is the small study population size. Additionally, the mean clinical follow-up time of these patients (<12 months) was not long enough to characterise post-PCl adverse cardiac events, and the diversity of stent types used may have confounded the interpretation of the results.

\section{CONCLUSIONS}

The SYNTAX score, when applied to a population of patients with low/moderate anatomic complexity treated with $\mathrm{PCl}$ in daily clinical practice, allows for risk stratification of medium-term MACE outcomes.

\section{CONFLICTS OF INTEREST}

The authors declare no conflicts of interest.

\section{REFERENCES}

1. Serruys PW, Morice MC, Kappetein AP, Colombo A, Holmes DR, Mack MJ, et al. Percutaneous coronary intervention versus coronary-artery bypass grafting for severe coronary artery disease. N Engl J Med. 2009;360(10):961-72.

2. Serruys PW, Onuma $Y$, Garg S, Sarno G, van den Brand M, Kappetein AP, et al. Assessment of the SYNTAX score in the Syntax study. Eurolntervention. 2009;5(1):50-6.

3. Sianos G, Morel MA, Kappetein AP, Morice MC, Colombo A, Dawkins K, et al. The SYNTAX score: an angiographic tool grading the complexity of coronary artery disease. Eurolntervention. 2005;1(2):219-27.
4. Valgimigli M, Serruys PW, Tsuchida K, Vaina S, Morel MA, van den Brand MJ, et al. Cyphering the complexity of coronary artery disease using the Syntax score to predict clinical outcome in patients with three-vessel lumen obstruction undergoing percutaneous coronary intervention. Am J Cardiol. 2007;99(8):1072-81.

5. van Gaal WJ, Ponnuthurai FA, Selvanayagam J, Testa L, Porto I, Neubauer S, et al. The Syntax score predicts peri-procedural myocardial necrosis during percutaneous coronary intervention. Int J Cardiol. 2009;135(1):60-5.

6. Mattos LA, Lemos PA, Rassi A Jr, Marin-Neto JA, Sousa AGMR Devito FS, et al. Diretrizes da Sociedade Brasileira de Cardiologia - intervenção coronária percutânea e métodos adjuntos diagnósticos em cardiologia intervencionista (II edição - 2008). Arq Bras Cardiol. 2008;91(6 Supl 1):1-58.

7. Cutlip DE, Windecker S, Mehran R, Boam A, Cohen DJ, van Es GA et al. Clinical end points in coronary stent trials: a case for standardized definitions. Circulation. 2007;115(17):2344-51.

8. Serruys PW, Daemen J, Morice MC, De Bruyne B, Colombo A Macaya C, et al. Three year follow-up of the ARTS-II - sirolimuseluting stents for the treatment of patients with multivessel coronary artery diease. Eurolntervention. 2008;3(4):450-9.

9. Windecker S, Serruys PW, Wandel S, Buszman P, Trznadel S, Linke $A$, et al. Biolimus-eluting stent with biodegradable polymer versus sirolimus-eluting stent with durable polymer for coronary revascularisation (LEADERS): a randomised noninferiority trial. Lancet. 2008;372(9644):1163-73.

10. Wykrzykowska JJ, Garg S, Girasis C, de Vries T, Morel MA van Es GA, et al. Value of the SYNTAX score for risk assessment in the all-comers population of the randomized multicenter LEADERS (Limus Eluted from A Durable versus ERodable Stent coating) trial. J Am Coll Cardiol. 2010;56(4):272-7.

11. Serruys PW, Silber S, Garg S, van Geuns RJ, Richardt G, Buszman PE, et al. Comparison of zotarolimus-eluting and everolimus-eluting coronary stents. N Engl J Med. 2010;363(2):136-46.

12. Tonino PA, De Bruyne B, Pijls NH, Siebert U, Ikeno F, van't Veer M et al. Fractional flow reserve versus angiography for guiding percutaneous coronary intervention. $N$ Engl J Med. 2009;360(3):213-24 